\title{
BMJ Open Perceptions of emergency care in Kenyan communities lacking access to formalised emergency medical systems: a qualitative study
}

\author{
Morgan C Broccoli, ${ }^{1}$ Emilie J B Calvello, ${ }^{2}$ Alexander P Skog, ${ }^{3}$ Benjamin Wachira, ${ }^{4}$ \\ Lee A Wallis ${ }^{5}$
}

To cite: Broccoli MC, Calvello EJB, Skog AP, et al. Perceptions of emergency care in Kenyan communities lacking access to formalised emergency medical systems: a qualitative study. BMJ Open 2015;5:e009208. doi:10.1136/bmjopen-2015009208

- Prepublication history and additional material is available. To view please visit the journal (http://dx.doi.org/ 10.1136/bmjopen-2015009208).

Received 26 June 2015 Revised 10 September 2015 Accepted 27 October 2015

CrossMark

\footnotetext{
${ }^{1} J o h n s$ Hopkins University, School of Medicine, Baltimore, Maryland, USA ${ }^{2}$ Department of Emergency Medicine, University of Maryland, Baltimore, Maryland, USA ${ }^{3}$ University of Maryland, School of Medicine, Baltimore, Maryland, USA ${ }^{4}$ Accident and Emergency Department, The Aga Khan University Hospital, Nairobi, Kenya

${ }^{5}$ Division of Emergency Medicine, University of Cape Town, Cape Town, South Africa
}

Correspondence to Morgan C Broccoli; morgan.broccoli@gmail.com

\section{ABSTRACT}

Objectives: We undertook this study in Kenya to understand the community's emergency care needs and barriers they face when trying to access care, and to seek community members' thoughts regarding high impact solutions to expand access to essential emergency services.

Design: We used a qualitative research methodology to conduct 59 focus groups with 528 total Kenyan community member participants. Data were coded, aggregated and analysed using the content analysis approach.

Setting: Participants were uniformly selected from all eight of the historical Kenyan provinces (Central, Coast Eastern, Nairobi, North Eastern, Nyanza, Rift Valley and Western), with equal rural and urban community representation.

Results: Socioeconomic and cultural factors play a major role both in seeking and reaching emergency care. Community members in Kenya experience a wide range of medical emergencies, and seem to understand their time-critical nature. They rely on one another for assistance in the face of substantial barriers to care-a lack of: system structure, resources, transportation, trained healthcare providers and initial care at the scene.

Conclusions: Access to emergency care in Kenya can be improved by encouraging recognition and initial treatment of emergent illness in the community, strengthening the pre-hospital care system, improving emergency care delivery at health facilities and creating new policies at a national level. These communitygenerated solutions likely have a wider applicability in the region.

\section{INTRODUCTION}

Recent attention has highlighted the need to integrate emergency care into existing healthcare systems. ${ }^{1-7}$ Delays in treatment of acute illness and injury are known to cause increased morbidity and mortality, ${ }^{1}{ }^{8-12}$ and the implementation of effective, prioritised,

\section{Strengths and limitations of this study}

- Access to quality emergency services is an essential component of the human right to health, but barriers to emergency care are found throughout Africa and the wider world.

- Data to support the development of emergency care are essential to improve access to care and further infrastructure development.

- We solicited input from community members for an initial needs assessment, encouraging shared ownership of the project to produce interventions that are more likely to be successful and sustainable.

- Focus groups were conducted in Swahili by trained facilitators, and were then translated and transcribed into English. While the potential exists for misinformation, as many words in Swahili do not directly translate, every effort was made to ensure that the collected data were representative and accurate.

- This study indicates the need for specific interventions to reduce barriers to access essential emergency services in Kenya, many of which are low cost: community first-aid education, training health providers in basic emergency care and triage protocols at health facilities.

timely emergency care has the potential to address $45 \%$ of deaths and $36 \%$ of disability in low-income and middle-income countries. ${ }^{6}$

In sub-Saharan Africa, health systems have traditionally addressed the burden of infectious diseases, but now face an increasing prevalence of non-communicable diseases and injury. ${ }^{13}$ Kenya typifies this epidemiological transition, with a clear need for horizontally integrated emergency care systems currently unmet by the public health system. ${ }^{14-17}$ The current Kenyan health system has 265 primary hospitals, 10 secondary hospitals and 4 tertiary hospitals, serving a population of over 45 million, 
approximately $78 \%$ of whom live in rural areas far from healthcare facilities. ${ }^{14-19}$ Emergency departments are typically staffed by clinical officers (mid-level providers with 3 years of clinical medicine training) who provide most of the country's emergency care, yet lack specific training in prioritisation, resuscitation and stabilisation. ${ }^{16}$ Most acutely ill and injured patients self-present at hospital, as the only public ambulance provider operates nine ambulances throughout the entire country, ${ }^{15}$ and private ambulances are not affordable for most. ${ }^{16}$

Although key strategic plans reference the need for emergency care systems in Kenya, there has been little progress in data gathering to augment system improvement, or in implementing interventions. ${ }^{16}{ }^{20}$ Data to support the development of emergency care and inform priority areas-specifically the community's experience -are essential to improve access to care and further infrastructure development. Soliciting input from community members for an initial needs assessment encourages shared ownership of projects, resulting in interventions that are more likely to be successful and sustainable. ${ }^{21}{ }^{22}$ We undertook this study in Kenya to understand the community's emergency care needs, barriers to their care and high impact solutions to expand access to essential emergency services.

\section{METHODS}

This study adapted and expanded on the qualitative methodology used in a Zambian pilot study. ${ }^{23}$ Focus groups were used to gather data, to encourage participation and to provide insight on a wide range of opinions, shared experiences and social norms. ${ }^{24} 25$ The investigators honed focus group questions from the pilot study that maximally yielded robust responses and elicited data about barriers to emergency care. 'Medical emergency' was explained to participants as any lifethreatening condition requiring emergency care, whether obstetric, traumatic or medical in nature-to differentiate from public health emergencies such as flooding. ${ }^{23}$

Four Kenyan healthcare providers were trained in best practices for focus group facilitation in a 4-day course. $^{23}{ }^{24}$ Facilitators were given dedicated time to translate the focus group script into Swahili and adapt it to local cultural expression. Swahili was chosen as it is one of two national languages, with English, and is the most commonly spoken language in Kenya. All facilitators contributed to the translation, which was then back translated into English as a quality control measure. The back translation was checked against the original English language version by two investigators (MCB and APS).

We sampled uniformly from all eight of the historical Kenyan provinces (Central, Coast, Eastern, Nairobi, North Eastern, Nyanza, Rift Valley and Western), with equal rural and urban community representation. Each facilitator visited urban and rural districts in two provinces, identified through the Kenyan Urban Areas and Cities Act. ${ }^{26}$ The only exception was Nairobi Province, as it does not technically contain any rural areas. For this province, purposeful sampling was used to conduct focus groups in urban upper-middle class areas, urban middle class areas, urban slums and periurban ('rural') areas.

Kenyan community members aged 18 years and older who spoke Swahili or English were eligible for inclusion. On arrival in the selected location, investigators approached a local community leader and provided full information on the study. The community leader then assisted in recruiting focus group participants. Five to 10 participants were selected using convenience sampling at each site, ${ }^{27}$ representing a range of participants in each group. Focus groups were conducted in each province until thematic saturation was reached for that province.

Focus group discussions were audio recorded and then immediately translated and transcribed into English by the facilitators who were fluent in both languages. These were then checked for accuracy by another Kenyan facilitator.

\section{Data analysis}

The lead investigator initially read all transcripts and identified key themes on which to construct a codebook within NVivo (QSR International Pty Ltd), using a content analysis approach. ${ }^{28} 29$ We selected a content analysis approach because it aids in making the results reliable and valid. ${ }^{28}$ The lead investigator then provided a detailed definition of each theme and code to a second investigator who would also be coding the data, including examples for each theme. After the second investigator coded several transcripts, inter-rater reliability was assessed. Once both investigators were coding consistently, each investigator independently coded half of the transcripts. ${ }^{30}$ The lead investigator went through the coded focus group scripts and aggregated the data by theme or by structural code. Thematic saturation was determined by the coding researchers when additional focus group data failed to identify participant sentiments that were unique to those previously expressed. Saturation was determined separately for each historical province, which increased validity by limiting the geographic heterogeneity of the population and exceeded guidelines for the number of interviews generally required to reach saturation. ${ }^{31}$ Questions identifying exposure to emergencies, and the type and frequency of emergencies witnessed, were coded in a structural fashion, and a coding frequency report was produced. ${ }^{29}$ Using NVivo, we undertook a thematic analysis to aggregate responses into larger groups; grouped responses were then classified as desire to provide assistance, barriers to emergency care, and ideas for how to improve access to emergency care.

Ethical approval was obtained from the University of Cape Town, the Aga Khan University Hospital Nairobi, 
the Kenyan National Commission for Science, Technology and Innovation, and the University of Maryland School of Medicine. Informed, written consent was obtained from each focus group participant: the consent form explicitly detailed the purpose of the study and the participant's role, in addition to their freedom to withdraw at any stage. No form of remuneration was made available to any participant.

\section{RESULTS}

We conducted 59 focus groups with 528 participants in the eight Kenyan provinces. A detailed breakdown of participants is included in online supplementary appendix S1. Results were analysed and compared for urban and rural locations, but as no substantial differences were found, we have only reported the totals.

\section{Exposure to medical emergencies}

Most participants understood the definition of a medical emergency to be a life-threatening medical condition requiring rapid or urgent treatment. No one gave an 'inappropriate' answer, although many offered specific diseases instead of a definition. Most had witnessed at least one medical emergency, with a significant number having witnessed three or more. When grouped by categories, traumatic emergencies were the most frequently mentioned, followed by medical and obstetric (table 1). There was little variability in the frequency with which different types of emergencies were reported between rural and urban communities.

Community members suffering medical emergencies reached healthcare facilities by a variety of different methods, with most respondents choosing private or public transport means and few using emergency services. Reported means of transport did not differ between rural and urban communities (box 1).

\section{Assistance and willingness to help}

Most participants had witnessed assistance being provided to the patient at the scene, usually first aid or transportation. Bystanders were most often referenced as providing help, along with family members, neighbours or friends. Community members demonstrated great willingness to help each other; most had helped in the past, and the overwhelming majority said they would help in the future. Participants reported that they would help due to feelings of moral obligation, a desire to relieve suffering and if they had the necessary training or resources. Participants also provided reasons why they might not help; the most common themes were lack of knowledge on how to assist, lack of personal protective equipment and the potential to cause inconvenience or harm to the helper. Specific concerns included that the helper might be blamed for the accident or involved in legal proceedings, or that they may need to answer many questions from police and doctors.
Table 1 Types of emergencies most commonly referenced

\begin{tabular}{ll}
\hline Trauma & Road traffic accidents \\
& Assault/mob justice \\
& Burns \\
& Blunt trauma \\
& Bleeding (traumatic) \\
& Fractures \\
Other trauma* & \\
& Penetrating trauma (stabbing, GSW) \\
Snakebites \\
Riots/mass casualty incidents \\
Sexual assault/rape \\
Electrocution \\
Suicide \\
Bites (dog, spider, crocodile) \\
Loss of consciousness \\
Difficulty breathing/asthma \\
Overdose/poisoning (alcohol, drugs, poisons, \\
pesticides) \\
Drowning \\
Seizures/epilepsy \\
Hypertension \\
Infection \\
Infectious disease exposure \\
Pneumonia \\
Non-traumatic bleeding (nose, ulcers, varicose \\
veins) \\
Malaria (cerebral) \\
Chest pain/heart attack \\
Foreign body (in airway) \\
'Sick' (non-specific) \\
Abdominal pain \\
Labour \\
Birth complications, ectopic pregnancy, \\
abortion complications \\
Obstetric
\end{tabular}

*Sports injuries, eye injuries, self-circumcision, accidents, being buried alive, children hurt while playing, hanging, overeating. GSW, gunshot wounds.

You can be afraid to help because in the example of road accidents, our government can arrest you on trumped up charges. You may be helping someone who is injured and when you take them to hospital only to realise that he was the thief which can get you in trouble.-Western

\section{Box 1 Types of transportation most commonly referenced}

Private cars

- Motorcycles

- Ambulances

- Taxis

- Walking or being carried

- Minibuses

- Police vehicles

- Tuk-tuks*

- Aircraft (planes and helicopters)

- School buses

- Lorriest

*Three-wheeled rickshaws, often used to transport passengers. †Trucks, often used for transporting goods. 
When asked how they would hypothetically provide help to someone suffering a medical emergency, many responded that they would help in any way they could. More specifically, participants answered that they would provide medical care (such as bleeding control) or transportation, or call for help. They also responded that they would be more likely to help if they had the necessary knowledge, skills and protective equipment.

I think people would help more if they knew what to do, so they need to be trained on first aid or lifesaving courses. -Nairobi

\section{Access to quality emergency care Barriers}

The barriers were grouped in five major themes: cost, system structure and lack of resources, transportation, healthcare providers, and initial care at the scene.

Cost

The most commonly referenced barrier was the high cost of treatment. This was particularly evident when participants spoke of private facilities, which were regarded as providing higher quality emergency care, but cost substantially more than government facilities.

In private hospitals they are very good and quick with emergencies but they want money which we don't have. In public hospitals people die in the queue waiting and nobody considers you.-Nyanza

\section{System structure}

The second most common barrier referenced was a lack of prioritisation protocols, causing critically ill patients to queue a long time before being seen. When grouped into larger themes, a non-functional system-one lacking triage, healthcare providers, resources and critical medications at facilities-was the most common barrier. Difficulties with communication such as unavailable emergency phone lines, prolonged admitting time due to paperwork before emergency care is provided and poor medical records systems, also contributed to difficulty accessing the system.

You may have a patient you took from home as an emergency then when you get to the hospital you find a long line and nobody is willing to assist you. So they can even die in line waiting to see the doctor and nobody cares.Nairobi

\section{Transportation}

Several barriers were transport related, including difficulty obtaining transportation and long distances required for travel (due to insufficient healthcare facilities and lack of emergency care after business hours).

\section{Healthcare providers}

Healthcare providers were seen as a substantial barrier to care. Participants felt that many providers were unfriendly towards patients or unmotivated to provide timely, appropriate care. Participants were also concerned about corruption; many felt that they were sent to buy medications that were unfairly priced, and witnessed physicians leaving the hospital during their working hours to work at private clinics. Participants felt that healthcare providers lack training in the basics of emergency care, and are unable to provide appropriate care.

\section{Initial care at the scene}

The final theme included barriers caused by initial care at the scene of an accident or illness. Participants felt that police caused barriers when they brought accident victims to the police station before taking them to the hospital. They also described how the individuals assisting during an emergency were often untrained and did not know how to properly care for the patient due to a lack of medical knowledge. Additional barriers to the provision of initial care at the scene of an accident included fear of police or looters, difficulty extricating the patient and general chaos.

Community is not aware of emergencies and how to deal with them so at times people just stand and stare.-Coast

\section{Ease of access}

Kenyan community members were specifically asked about factors that make it easier to access emergency care. The most common response was that patientspecific qualities make accessing emergency care easier. Participants related that they had an easier time accessing emergency care when they were dressed well, had a good attitude and showed patience, had personal financial resources or insurance and personally knew a healthcare provider. Other factors included having available transportation, seeking care at a good healthcare facility such as one in the private sector and having neighbours with first aid knowledge.

My brother told me that if you want to be treated well and survive in Kenya, you need to shave neatly and wear a suit; you will be attended to very fast if you have an emergency.-Western

\section{Community-identified solutions to improve access to quality emergency care}

When asked for ideas that would improve their access to emergency care, focus group participants identified many interventions.

\section{Improved emergency care system structure}

Many of the recommendations involved improving the structure of the emergency care system. Participants wanted improved material resource availability at all 
levels, from gloves and first aid kits in their communities to resuscitation equipment and stocked medications in hospitals. They recommended designated areas for emergency care in facilities where patients would be triaged and treated according to the severity of their case. Communication was another area of concern; participants felt that there should be one central, accessible, functional emergency number for the entire country. Participants also felt that their government should pay healthcare providers better, manage healthcare facilities to reduce corruption, streamline the referral system and enact laws requiring provision of medical care to occur before paperwork, police investigation or payment.

If there was a separate emergency section it'd help as opposed to being made to queue with everyone else.Coast

\section{Improved healthcare providers}

Another significant theme was that access to emergency care could be improved by increasing the numbers of healthcare providers, by training providers in emergency care and by having dedicated emergency care providers. Participants also thought that provision of care could be improved by paying providers more, and by penalising providers who accept bribes or who work at private clinics during their public hospital shifts.

\section{Improved transportation}

Transportation and physical access to healthcare facilities were other areas where participants felt there should be improvement. Suggestions included increasing the number of ambulances, numbering houses for easier ambulance dispatch, increasing the number of healthcare facilities or clinics in remote areas and increasing clinic hours to allow for emergency care at all hours of the day.

\section{Community capacity building}

Emergency care capacity building at the community level was the second most commonly requested intervention. Participants predominately wanted community first responder training, so they could appropriately care for their neighbours when needed. They also felt that communities should have general 'emergency awareness' classes that teach everyone to recognise medical emergencies and how to obtain assistance.

I think first aid should be taught to people in the community. Learning basic first aid skills would help because sometimes people fail to help due to lack of knowhow.North Eastern

\section{Decreased cost of care}

Many participants also wanted to see decreased costs of healthcare treatment, including less expensive medications, reduced costs at private hospitals, increased insurance coverage and subsidised healthcare.

\section{LIMITATIONS}

While every effort was taken to ensure that the research was methodologically sound, two limitations need to be considered. Most focus groups were conducted in Swahili, then translated and transcribed into English. While the potential exists for misinformation, as many words in Swahili do not directly translate, a second facilitator was used to back translate, with verification provided by a third independent auditor. Also, the investigators themselves did not conduct the focus groups, which could lead to lost opportunities for more meaningful exploration of important opinions. Kenyan healthcare providers were utilised as it was crucial to have the focus groups conducted in the local language by individuals from the community. However, they are unlikely to have had a full understanding of the study, meaning that our coding results needed to be more robust.

Using translators to mediate the focus groups would not have been successful, as such discussions rely on group dynamics and participation. The Kenyan facilitators were rigorously selected and trained, and first conducted trial focus group sessions to determine their ability to consistently and accurately direct the discussion.

\section{DISCUSSION}

This study improves on the community-centred methodology first piloted in Zambia to solicit community members' experiences with access to emergency care and their priority interventions to improve the Kenyan emergency care system. ${ }^{23}$

Conceptually, access to healthcare has been described using the pillars of availability, acceptability and affordability, with notable variations. ${ }^{32-34}$ While such models may be functional in the world of health policy, everyday emergencies require acknowledgement of time-dependent, appropriate clinical care in order to maximise clinical outcomes. The recent literature has referenced the applicability of the 'three delays' model (a framework initially developed for obstetric care) to describe provision and utilisation of effective, timely emergency care. ${ }^{32} 35$ The delays described include the decision to seek care, reaching care and receiving appropriate care, and are influenced by socioeconomic and cultural factors, accessibility of healthcare facilities and quality of care provided. ${ }^{35} 36$

Socioeconomic and cultural factors (such as community understanding of, and prior experience with, emergencies) play a major role both in deciding to seek care and in reaching care. Participants in this study have experienced a wide range of medical emergencies, and seem to understand their time-critical nature. They rely on family members, neighbours and 'good Samaritans' for assistance, often with transportation to healthcare facilities and basic first aid. But untrained bystanders and police officers may add to delays, such as when officers take patients to the police station before taking them to the hospital. And 
although community members are the primary source of assistance during emergencies, and are willing to continue helping one another, many are concerned that they place themselves at risk by helping; these fears must be addressed through education and governance to protect responders before community-based interventions to increase access can be successful. ${ }^{37}$

Accessibility of healthcare facilities also affects both the decision to seek care and how quickly one is able to reach a facility. Transportation barriers appear common; due to the paucity and cost of transportation, private transport is most frequently used. This is consistent with other Kenyan studies showing that most road traffic crash victims are transported by private cars and taxis. ${ }^{38} 39$ The frequency of ambulance use is low; in addition to poor availability, in most cases, ambulances function only as a taxi, as very few have either trained attendants or necessary equipment. ${ }^{16}$ In fact, waiting for an ambulance rather than taking the most immediately available form of transportation may delay time to definitive care. Other important accessibility barriers include an inadequate number of healthcare facilities resulting in substantial travel distances, lack of care outside of business hours and absence of a centralised emergency phone number.

The quality of emergency care services ultimately affects the decision to seek care and the delivery of appropriate treatment. At healthcare facilities, a lack of triage, insufficient trained providers and scarce resources prohibit the delivery of effective emergency care, and leave community members dissatisfied. Cost of care is also a substantial barrier; participants agreed that private facilities offered better emergency care, yet, due to high costs, if they sought care they did it at government facilities.

Community members in this study drew on their personal experiences to identify multiple barriers to emergency care, along with ideas for improving access. The community generated solutions are consistent with those elicited from Zambian community members, and likely have a wider applicability in the region. ${ }^{23}$

\section{Early recognition and initial treatment of emergent illness in the community}

Community members and police officers have no training in the initial recognition, stabilisation and transport of emergency patients, although they are the first (and often only) available help. With training, such responders can recognise emergent conditions and appropriately utilise available resources to avoid unnecessary delays in care. ${ }^{36-40}$ Early care for critical illness is one of the most essential interventions, as delays result in increased morbidity and mortality. ${ }^{10-12}$ Basic first aid training increases the likelihood that community members will assist in an emergency, improving their knowledge and skills and empowering them to take precautions to ensure their own safety. ${ }^{37} 454748$
Strengthen the pre-hospital care system to augment patients' ability to reach care

Kenya has too few ambulances, they are not part of a unified system and most do not provide care, focusing only on transportation. Creating a single national emergency number would allow community members to request emergency help when needed. Focus should then be placed on increasing the availability of emergency transportation and ambulance staff trained to provide basic emergency care; there is ample evidence that emergency transportation to appropriate care saves lives. ${ }^{3} 4950$

\section{Improve appropriate emergency care delivery at health} facilities via training and process improvement

Lack of properly trained healthcare providers, triage systems, dedicated space and equipment for emergency care, and lack of a timely, effective referral system at healthcare facilities, all contribute to delays in receiving quality emergency care. ${ }^{36}$ All levels of the healthcare system should have certified healthcare providers with dedicated training to recognise and treat acutely ill and injured patients. We recommend that training initially focus on providers working in clinics and district hospitals, as well as those working in the emergency intake areas of larger hospitals. ${ }^{3} 51$

At the facility level, many barriers could be diminished by simple re-structuring of patient flow. Context-appropriate triage systems should be implemented at all facilities, to maximise the efficient use of resources while minimising overall morbidity and mortality. ${ }^{52}$ It is also important to create dedicated spaces for emergency care in facilities, and to equip these with basic supplies needed for resuscitation. All facility-level improvements should be prioritised at lower level facilities, as emergent patients generally present to their closest healthcare facility, and must be stabilised before they can be safely transferred to a higher level of care.

\section{Improve the regulatory environment around everyday emergencies}

The creation of new policies at a national level would reduce several barriers. Community members worry about helping one another because they fear being involved in a legal case, or being blamed for the incident. Many countries have 'good Samaritan' laws that protect bystanders who provide assistance to others in emergency situations. If community members felt that they would be protected from legal harm, they may be more likely to assist.

Requiring paperwork and payment before provision of medical care creates a significant barrier, and is easily eliminated by requiring that emergent patients be stabilised immediately on arrival. Although Kenya's Constitution prohibits denying anyone emergency medical treatment, ${ }^{53}$ initial delays caused by paperwork and payment have the potential to cause significant morbidity and mortality. Poor health worker pay was noted to 
have a negative effect on patient care, and improved incentives could enhance their motivation and commitment, and alleviate their need for a second job. ${ }^{54}$

This study indicates the need for specific interventions to reduce barriers to access essential emergency services in Kenya. Participants identified solutions at all levels of the health system. A few of the proposed solutions, such as creation of a unified pre-hospital system, need substantial financial investment, requiring an urgent prioritisation process within the Kenyan government. Most community-based solutions, however, are low cost, including community first aid education, training health providers in basic emergency care and simple process changes such as triage protocols at health facilities. The challenges of community access to emergency care are not unique to Kenya. The themes of difficulty in seeking care, reaching care and receiving appropriate emergency care are found throughout healthcare systems in Africa. Communities themselves have the capacity to identify barriers and generate essential steps to address the most often overlooked component in their right to health-the right to quality emergency services.

\section{Twitter Follow Alexander Skog at @alex_Skog}

Acknowledgements The authors would like to thank the collaborators Lavinia Bwisa, Lydia Ogunde, Javan Kado and Irungu Wangechi, who facilitated the focus group discussions, and Mary Li for her help with the facilitator training. They would also like to thank the University of Maryland School of Medicine, Johns Hopkins University Department of Emergency Medicine, and Sarah Stewart de Ramirez, for their support of this project.

Contributors MCB, EJBC, BW and LAW conceived the study, designed the trial and obtained research funding. MCB, EJBC, APS and BW supervised the conduct of the trial and data collection. MCB and APS coded and analysed the data. MCB drafted the manuscript, and is the guarantor. All the authors contributed substantially to the article's revision.

Funding This research received a grant for US $\$ 10,000$ from the University of Maryland School of Medicine to cover the costs associated with the study.

Competing interests None declared.

Ethics approval The University of Cape Town, The Aga Khan University Hospital Nairobi, The Kenyan National Commission for Science, Technology and Innovation, and the University of Maryland School of Medicine.

Provenance and peer review Not commissioned; externally peer reviewed.

Data sharing statement No additional data are available.

Open Access This is an Open Access article distributed in accordance with the Creative Commons Attribution Non Commercial (CC BY-NC 4.0) license, which permits others to distribute, remix, adapt, build upon this work noncommercially, and license their derivative works on different terms, provided the original work is properly cited and the use is non-commercial. See: http:// creativecommons.org/licenses/by-nc/4.0/

\section{REFERENCES}

1. Calvello EJB, Broccoli M, Risko N, et al. Emergency care and health systems: consensus-based recommendations and future research priorities. Acad Emerg Med 2013;20:1278-88.

2. Reynolds TA, Calvello EJB, Broccoli MC, et al. AFEM consensus conference 2013 summary: emergency care in Africa-where are we now? Afr J Emerg Med 2014;4:158-63.

3. Razzak JA, Kellermann AL. Emergency medical care in developing countries: is it worthwhile? Bull World Health Organ 2002;80:900-5.

4. World Health Organization: Sixtieth World Health Assembly. Resolution WHA 60.22: emergency-care systems. Geneva: World
Health Organization, 2007. http://www.who.int/gb/ebwha/pdf_files/ WHA60/A60_R22-en.pdf.

5. Jamison DT, Breman JG, Measham AR, et al. Disease control priorities in developing countries. World Bank Publications, 2006

6. Kobusingye OC, Hyder AA, Bishai D, et al. Emergency medical services. World Bank, 2006. http://www.ncbi.nlm.nih.gov/books/ NBK11744/

7. Marsh RH, Rouhani SA, Pierre P, et al. Strengthening emergency care: experience in central Haiti. Lancet Glob Health 2015;3(Suppl 2):S5-7.

8. Murray CJ, Frenk J. A framework for assessing the performance of health systems. Bull World Health Organ 2000;78:717-31.

9. The world health report 2000-Health systems: improving performance. WHO. http://www.who.int/whr/2000/en/

10. Gaieski DF, Mikkelsen ME, Band RA, et al. Impact of time to antibiotics on survival in patients with severe sepsis or septic shock in whom early goal-directed therapy was initiated in the emergency department. Crit Care Med 2010;38:1045-53.

11. Crandall $M$, Sharp $D$, Unger $E$, et al. Trauma deserts: distance from a trauma center, transport times, and mortality from gunshot wounds in Chicago. Am J Public Health 2013;103:1103-9.

12. McCoy CE, Menchine M, Sampson S, et al. Emergency medical services out-of-hospital scene and transport times and their association with mortality in trauma patients presenting to an urban Level I trauma center. Ann Emerg Med 2013;61:167-74.

13. Marquez PV, Farrington JL. The challenge of non-communicable diseases and road traffic injuries in sub-Saharan Africa: an overview. 2013. https://openknowledge.worldbank.org/handle/10986/16451

14. Wachira BW, Wallis LA, Geduld H. An analysis of the clinical practice of emergency medicine in public emergency departments in Kenya. Emerg Med J 2012;29:473-6.

15. Wachira BW, Smith W. Major incidents in Kenya: the case for emergency services development and training. Prehosp Disaster Med 2013;28:170-3.

16. Wachira B, Martin IBK. The state of emergency care in the Republic of Kenya. Afr J Emerg Med 2011;1:160-5.

17. Ministry of Medical Services and Ministry of Public Health and Sanitation. Republic of Kenya Health Sector Strategic Plan for Health Information System 2009-2014. http://apps.who.int/ healthmetrics/library/countries/HMN_KEN_StrPlan_Final_2010_02_ en.pdf

18. Ministry of Medical Services and Ministry of Public Health and Sanitation. e-Health Kenya facilities. http://www.ehealth.or.ke

19. Luoma M, Doherty J, Muchiri S, et al. Kenya health system assessment 2010. Bethesda, MD: Abt Associates Inc, 2010. http:// www.cmamforum.org/Pool/Resources/Kenya-HSA-Report-Final2010.pdf

20. Ministry of Medical Services and Ministry of Public Health and Sanitation. Accelerating attainment of health goals: The Kenyan Health Sector Strategic and Investment Plan (KHSSP), July 2013June 2017. http://www.who.int/pmnch/media/events/2013/kenya hssp.pdf

21. Wright $\mathrm{J}$, Walley $\mathrm{J}$. Health needs assessment: assessing health needs in developing countries. BMJ 1998;316:1819-23.

22. Barnett $\mathrm{K}$. Best practices for community health needs assessment and implementation strategy development: a review of scientific methods, current practices, and future potential. Atlanta, GA: The Centers for Disease Control and Prevention, 2012. http://www.phi. org/uploads/application/files/ dz9vh55o3bb2×56lcrzyel83fwfu3mvu24oqqvn5z6qaeiw2u4.pdf

23. Broccoli MC, Calvello EJB, Twomey M, et al. Community-based perceptions of emergency care in communities lacking formalized emergency medicine systems. Ann Emerg Med 2014;64: S73-74.

24. Dawson S, Manderson L, Tallo VL. Countries INF for D, diseases UBSP for R and T in T. A manual for the use of focus groups. 1993. http://apps.who.int//iris/handle/10665/41795

25. Krueger RA. Focus groups: a practical guide for applied research, 3rd edn. Thousand Oaks, CA: Sage Publications, 2000. https:// catalyst.library.jhu.edu/catalog/bib_2154300

26. The National Council for Law Reporting. The Urban Areas and Cities Act. 2011. http://siteresources.worldbank.org/INTAFRICA/Resources/ 257994-1335471959878/Urban_Areas_and_Cities_Act_2011.pdf

27. Rabiee F. Focus-group interview and data analysis. Proc Nutr Soc 2004:63:655-60.

28. Silverman D. Interpreting qualitative data: methods for analyzing talk, text and interaction. SAGE, 2006.

29. Guest G, MacQueen KM. Handbook for team-based qualitative research. Rowman Altamira, 2007.

30. Mwaka AD, Okello ES, Orach CG. Barriers to biomedical care and use of traditional medicines for treatment of cervical cancer: an 
exploratory qualitative study in northern Uganda: reasons for use of traditional medicine. Eur J Cancer Care 2015;24:503-13.

31. Mason M. Sample size and saturation in PhD studies using qualitative interviews. Forum Qualitat Soc Res 2010;11:3. http:// nbn-resolving.de/urn:nbn:de:0114-fqs100387

32. Penchansky R, Thomas JW. The concept of access: definition and relationship to consumer satisfaction. Med Care 1981;19:127-40.

33. Gulliford M, Figueroa-Munoz J, Morgan M, et al. What does "access to health care" mean? J Health Serv Res Policy 2002;7:186-8.

34. Mclntyre D, Thiede M, Birch S. Access as a policy-relevant concept in low- and middle-income countries. Health Econ Policy Law 2009;4 (Pt 2):179-93.

35. Calvello EJ, Skog AP, Tenner AG, et al. Applying the lessons of maternal mortality reduction to global emergency health. Bull World Health Organ 2015;93:417-23.

36. Thaddeus S, Maine D. Too far to walk: maternal mortality in context. Soc Sci Med 1994;38:1091-110.

37. Sun JH, Wallis LA. The psychological effects of widespread emergencies and a first responder training course on a violent, developing community. Afr J Emerg Med 2011;1:166-73.

38. Mogaka EO, Ng'ang'a Z, Oundo J, et al. Factors associated with severity of road traffic injuries, Thika, Kenya. Pan Afr Med J 2011;8:20. http://www.ajol.info/index.php/pamj/article/view/71076

39. Saidi HS, Kahoro P. Experience with road traffic accident victims at The Nairobi Hospital. East Afr Med J 2001;78:441-4.

40. Mock CN, Tiska M, Adu-Ampofo M, et al. Improvements in prehospital trauma care in an African country with no formal emergency medical services. J Trauma 2002;53:90-7.

41. Geduld H, Wallis L. Taxi driver training in Madagascar: the first step in developing a functioning prehospital emergency care system. Emerg Med J 2011;28:794-6.

42. Sun $\mathrm{JH}$, Shing $\mathrm{R}$, Twomey $\mathrm{M}$, et al. A strategy to implement and support pre-hospital emergency medical systems in developing, resource-constrained areas of South Africa. Injury 2014:45:31-8.

43. Jayaraman S, Mabweijano JR, Lipnick MS, et al. Current patterns of prehospital trauma care in Kampala, Uganda and the feasibility of a
Lay-First-Responder training program. World J Surg 2009;33:2512-21.

44. Sun JH, Wallis LA. Learning and retention of emergency first aid skills in a violent, developing South African township. Emerg Med $J$ 2013;30:161-2.

45. Tiska MA, Adu-Ampofo M, Boakye G, et al. A model of prehospital trauma training for lay persons devised in Africa. Emerg Med $\mathrm{J}$ 2004;21:237-9.

46. Barnes-Josiah D, Myntti C, Augustin A. The "three delays" as a framework for examining maternal mortality in Haiti. Soc Sci Med 1998;46:981-93.

47. Husum $\mathrm{H}$, Gilbert M, Wisborg $\mathrm{T}$, et al. Rural prehospital trauma systems improve trauma outcome in low-income countries: a prospective study from North Iraq and Cambodia. J Trauma 2003;54:1188-96.

48. Wisborg T, Murad MK, Edvardsen O, et al. Prehospital trauma system in a low-income country: system maturation and adaptation during 8 years. J Trauma 2008;64:1342-8.

49. Samai O, Sengeh P. Facilitating emergency obstetric care through transportation and communication, Bo, Sierra Leone. Int J Gynaecol Obstet 1997;59(Suppl 2):S157-64.

50. Arreola-Risa C, Mock CN, Lojero-Wheatly L, et al. Low-cost improvements in prehospital trauma care in a Latin American city. J Trauma 2000;48:119-24.

51. Burke TF, Hines R, Ahn R, et al. Emergency and urgent care capacity in a resource-limited setting: an assessment of health facilities in western Kenya. BMJ Open 2014;4:e006132.

52. Wallis LA, Gottschalk SB, Wood D, et al. The cape triage score-a triage system for South Africa. S Afr Med J 2008;96:53.

53. Wachira BW. Kenya: 2013 field report. Emerg Physicians Int., 2013. http://www.epijournal.com/articles/93/kenya-2013-fieldreport

54. Gow J, George G, Mutinta G, et al. Health worker shortages in Zambia: an assessment of government responses. J Public Health Policy 2011;32:476-88. 